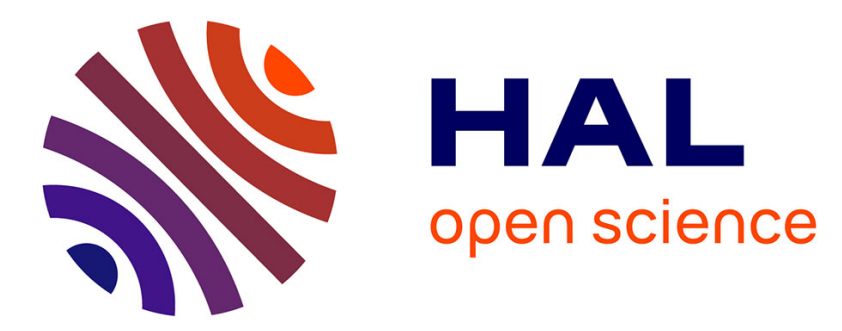

\title{
Enacting Innovation within Collaborative-Driven SOA Providers Networks
}

Joao Ferreira Santanna, Ricardo J. Rabelo, Alexandra A. Pereira-Klen

\section{To cite this version:}

Joao Ferreira Santanna, Ricardo J. Rabelo, Alexandra A. Pereira-Klen. Enacting Innovation within Collaborative-Driven SOA Providers Networks. IFIP International Conference on Advances in Production Management Systems (APMS), Sep 2014, Ajaccio, France. pp.399-408, 10.1007/978-3-66244733-8_50. hal-01387278

\section{HAL Id: hal-01387278 \\ https://inria.hal.science/hal-01387278}

Submitted on 25 Oct 2016

HAL is a multi-disciplinary open access archive for the deposit and dissemination of scientific research documents, whether they are published or not. The documents may come from teaching and research institutions in France or abroad, or from public or private research centers.
L'archive ouverte pluridisciplinaire HAL, est destinée au dépôt et à la diffusion de documents scientifiques de niveau recherche, publiés ou non, émanant des établissements d'enseignement et de recherche français ou étrangers, des laboratoires publics ou privés.

\section{(c)(1)}

Distributed under a Creative Commons Attribution| 4.0 International License 


\title{
Enacting innovation within collaborative-driven SOA providers networks
}

\begin{abstract}
Software industry has become a very important sector nowadays. New ICT paradigms have emerged to cope with current global-local world challenges, such as Service-oriented architecture (SOA). SOA has the potential to raise SMEs to new levels of sustainability in terms of software innovation. However, SMEs are limited in their resources, and both innovation and SOA are complex, costly and risky. This paper presents preliminary results of an ongoing research towards developing an innovation model that relies on collaboration, enabling software/SOA providers to work as an open network to jointly develop an innovative SOA-base software product. The proposed model identifies not only the processes to be involved in but also identifies the most relevant supporting issues to be taken into account along the innovation and collaboration processes. Final considerations about the work are presented at the end.
\end{abstract}

Keywords - Collaborative Networks; Innovation; Software Services; SOA.

\section{Introduction}

Software industry has become a very important sector nowadays. In Europe, for instance, there are more than fifty thousand SMEs within the ICT sector [1]. Being by far composed of SMEs, they usually have tough difficulties for engaging assets to feasibly invest on innovation with acceptable risk [2]. So it is crucial to develop sustainable models to allow them taking advantage of more recent ICT and organizational trends and hence to innovate. $\mathrm{Li}$ et al. [3] point out that software innovation is a key aspect to increase SMEs competitiveness.

Some recent ICT paradigms have emerged with the potential to support that. This paper deals with SOA (Service Oriented Architecture) paradigm. SOA represents a new vision in terms of systems design, development, integration and servitization. In the SOA vision, all system's features are seen as independent and self-contained software modules - called software services - that jointly form virtually a single logical unit to create products and processes [2]. There are some technologies for implementing services-based systems, being web services the most used one.

Reports anticipate a SOA market of \$15 billion dollars in 2019 [4]. However, SOA projects are complex, risky, costly and unique, impacting companies (both customers and providers) at many dimensions [2]. This paper exploits the premise that SOA providers SMEs can mitigate such barriers if they collaborate more intensively with each other towards jointly developing SOA-based innovative software products.

It is important to highlight that a SOA/software product has many differences when compared to manufacturing sector/product, in terms of e.g. development stages and 
methodologies, supporting constructs, physical deployment, SLA treatment, software / services quality, and product contracting, access and usage.

Working collaboratively is rather difficult. Companies are heterogeneous and autonomous, largely distributed, meaning that their different strategies must be accommodated and interoperate regarding their different priorities and trade-offs in terms of acceptable risks, trust and benefits [5].

A sort of collaborative/networked-based innovation models have been presented in the literature. However, none of them are devoted to SOA/software sector and do not consider a wider open scenario where services' providers can participate in all phases of the innovation process, collaboratively and as a network, sharing benefits, costs and risks. Besides that, most of models are very abstract, without providing more detailed processes and even less for a collaborative SOA scenario.

This paper shows preliminary results of an ongoing research which aims to contribute to face this gap, presenting an innovation model that deals with that general scenario. It has been conducted as an essentially research-action, qualitative, deductive and applied work, strongly grounded on literature revision.

The paper is organized as follows. Section has introduced the problem and research goals. Section 2 presents a basic foundations review. Section 3 introduces the proposed model. Section 4 provides a summary of the achieved results and next steps.

\section{Basic concepts and revision of the state-of-the-art}

This section presents a resumed description of the main core theoretical foundations that have been used in the conception of the proposed innovation model.

\subsection{Innovation models}

By innovation model it is meant the general conceptual construct that helps an organization and its actors to set up the innovation framework, to develop the innovation itself and to manage this progress and its results (adapted from [6]). The literature presents an extensive list of innovation models. In essence, they basically describe the main phases and general processes necessary to carry an innovation out via the socalled funnel, namely: selection and/or generation of ideas, concept development, concept evaluation/selection, concept design/specification, implementation and exploitation (adapted from [7]).

Innovation models have evolved from linear models to network and open models, which can go back and forth through each phase (stage). Evaluation actions (gate) use to be added between each stage so releasing or not the process continuation. Different actors can contribute along the innovation process' stages, being them intraorganizational members or external partners/stakeholders, and even customers [8].

Regarding this paper's goal, two innovation models are of particular relevance: the Network and Open innovation models. Roughly, the Network model considers an open environment composed of companies prepared and willing to work on an innovative idea when it comes up. Processes and operating rules are then set up accordingly. Open innovation focuses on a new logic based in openness and collaboration. It has been often adopted by large corporations that have the innovative idea reasonably well clear and looks for some complementarities and added value in some processes or product's parts. This can come from established partners or from wider ecosystems.

\subsection{Collaborative Networks}

$\mathrm{CN}$ is a general concept that embraces the diverse manifestations of collaboration among organizations. Its essentials relies on allowing organizations to keep focused on 
their skills and aggregating competencies and diverse resources with other organizations - so creating networked organizations - in order to offer products with higher value to meet businesses in a better way [8].

Two manifestations are of particular importance in this work: VO (Virtual Organization) and VBE (Virtual organization Breeding Environments). Generally, a VO can be defined as a temporary alliance formed by autonomous and heterogeneous organizations that collaboratively join their complementary core-competences and resources to better attend to a given demand, dismantling itself after all its legal obligations have been accomplished. During its lifecycle (VO creation, operation, evolution and dissolution), new members can get in and existing members can get out from it. VOs are mostly originated from long-term alliances, namely a VBE. A VBE formally groups organizations aiming at creating VOs with the most adequate partners in a more agile and trustful way, thanks to enough pre-conditions and basic/common operating rules for collaboration which are set up when its members get into it [9].

A VBE is classically seen as a closed world, not supporting larger and open digital business ecosystem at all. Adaptations in the VBE concept towards handling such more ample scenarios have been proposed, as the Federation [5] and the sectoral system innovation [10] concepts.

\subsection{Governance}

Governance in Networked Enterprises can be defined as "the definition of rules, criteria for decision-making, responsibilities, and boundaries of actions and autonomy for the involved actors. It is created by the own set of organizations to regulate itself. The fundamental role of governance is not managing, but rather to delimitate the management. Actors can use their knowledge within the defined governance framework in way to help organizations to best reaching their common goals" [11] .

During the collaboration life cycle companies share assets and sensible information. However, they are independent enterprises and have their own business strategies, creating a complex and intrinsically conflicting operating scenario. Therefore, it is extreme relevant to properly govern that in way to minimize conflicts among all the involved actors and hence the risks for achieving the innovation goals.

In the $\mathrm{CN}$ perspective, a VO embraces different partners, with different roles and hence rights and duties, according to the business' profile, VO life cycle and the VBElike/network's principles, bylaws and rules. This should be regulated by the VBE-like and VO governance models. Costa et al. [12] have proposed an integrated VBE-VO governance model on top of some classical network governance models, e.g. [13] [14].

\subsection{State-of-the-Art}

The Systematic Literature Review methodology [15] was applied to support the state-of-the-art review. IEEExplore, ACM, and ScienceDirect databases were searched, collecting papers written in English and published in journals and conference proceedings in the period Jan 2000-Feb 2014. It also considered some ad-hoc searches over the Internet and a search at CORDIS, the EU research projects database.

Any work was found out which dealt with the envisaged open and networkedbased innovation models and devoted to SOA \& software providers. On the other hand, 5 papers and 6 projects presented more useful insights for the proposed innovation model, its processes and constructs.

Du Preez et al. [7] have devised an innovation model for products and general services (i.e. not for software services) identifying the most important required macro processes. Berre et al. [16] have proposed supporting languages to express the value 
delivery and services chain for the general area of services. Hoyer et al. [17] have stressed the obstacles faced by SMEs when collaborating. Belussi et al. [18] have proposed a framework and services typology in the innovation context. Therefore, they are all innovation initiatives on services but anyone on software services/SOA. Li et al. [3] have proposed a model driven collaborative development platform for SOA-based e-business systems, but not devoted anyhow to support innovation.

In terms of EU projects, BIVEE, ComVantage, IMAGINE, CoVES, Laboranova and PLENT [19] have tackled innovation at different perspectives and levels, fundamentally devoted to manufacturing sector, some considering the open innovation model, some don't. Anyone has applied the network innovation model and/or more directed to software or SOA sector.

\section{Proposed Innovation Model}

\subsection{General Requirements and rationale}

Regarding the various aspects mentioned in the previous sections, the innovation model basically intends to endow groups of SOA-related and supporting software SMEs (belonging to a federation-like ecosystem) to carry an innovation out towards providing a (SOA) software (product) solution to attend to a given request.

In order to devise the model, this vision was decomposed into fifteen specific requirements. In a resumed way, the most relevant ones are: i) The 'product' is a SOAbased software, composed of existing web services; ii) Different companies own services or are in charge of developing such services; iii) This ownership should be protected and accounted; iv) Each web service and its supporting infrastructure can be developed / provided by one or by more companies or ad-hoc supporting partnerships; v) Companies that will participate in the innovation process should be properly selected; vi) Companies may participate along the entire innovation process and related software development cycle, depending on their agreed roles, rights and duties; vii) Companies may/can/should enter to, operate in, and exit from the collaborative innovation network in different moments and number of times, both in the normal operation of the network and when problems, changes or severe conflicts take place.

The model's structure took the "classical" processes proposed by Du Preez at al. [7] into account (section 2.1) as they can comprehensively embrace the general processes necessary for the envisaged model. Processes' names and sub-processes were adapted to better reflect their role regarding the intrinsic nature of SOA development.

Regarding that SOA \& supporting software providers have web services assets and related expertizes, it is also important that the necessary expertizes can be joined, covering the diverse dimensions involved in an innovation, such as legal, financial, commercial, technological and software engineering.

\subsection{The Proposed Innovation Model}

The model is showed in Fig 1. It also uses the funnel notion to represent the multiple ideas that go through evaluation phases where only the approved ideas can go on.

However, differently from the classical models, the funnel is here split into two sequential but somehow decoupled macro phases. Whilst the first funnel aims to discuss and select the best ideas and then to define the respective members of the innovation network (i.e. $\mathrm{t} \mathrm{VO}$ ), the second one aims to develop the selected innovation(s) inside the formed $\mathrm{VO}(\mathrm{s})$. This separation is also important as there are different notions of budget, time and $\mathrm{H}$ resources allocations, the importance of the research, and the involvement of customers, experts and external supporting entities in each funnel. 
Processes and nature of discussions, type of knowledge, information flow, type of responsibilities, etc., are intrinsically different in each funnel. Regarding that, the innovation behaves more like as the network type inside the first funnel and more like as the open innovation type in the second funnel. In terms of governance model, while the all-ring no-core and buyer-driven models $[13,14]$ tends to largely prevail in the first funnel, this tends to be more core-ring with coordination firm and information-driven in the second funnel. The innovation can move forward and backward in both funnels. However, this tends to happen much more frequently in the first funnel due to the natural not so structured way of exchanging more abstract/business ideas towards more concrete plans. In the second funnel this tends to be more controlled, based on evaluations performed in the intermediate gates (illustrated as "vertical lines" separating the processes within the funnels), deciding if the whole process can go on or not (and further actions). This decision involves interactions among partners, observing the governance model. It can be said that a more human-driven approach tends to predominate in the first funnel and a process-driven approach tends to do so in the second funnel, where the (software) development process is usually well defined and more structured.

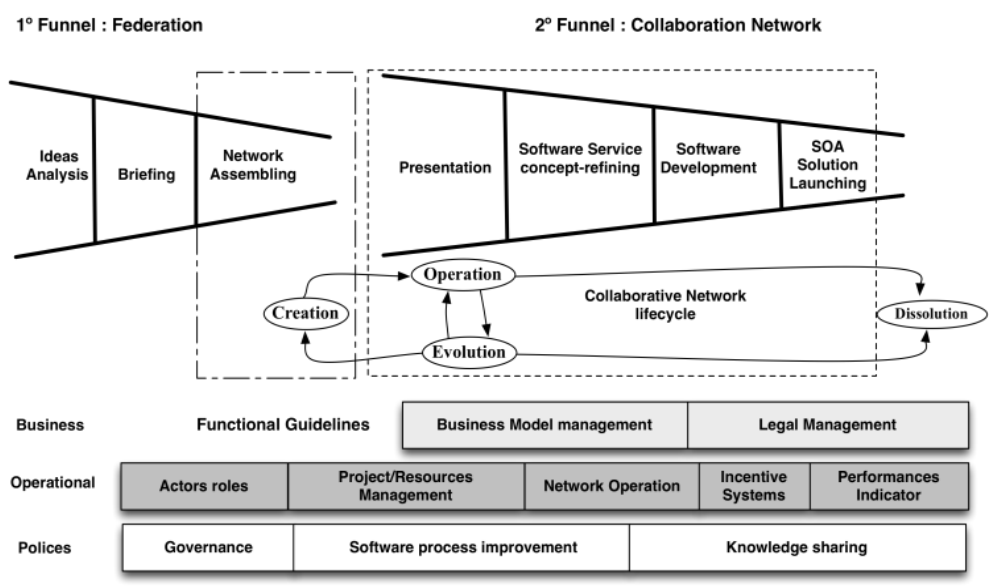

Fig. 1. The proposed Innovation Model. Source: authors.

Briefly, the processes are the following:

First funnel

1) Idea Analysis: one (or group of) company from the federation can propose a joint innovation to the federation's committee, which will firstly evaluate the idea's potential. At this moment the idea is presented shallowly.

2) Briefing: the idea is now detailed presented, describing the necessary technologies, potential partnerships, estimated ROI, foreseen market, etc.

3) Network assembly: formation of the VO that will execute the innovation. It involves partners' search and selection, negotiation, VO governance model and revenue mode setting up, and contract signature. Yet, performance indicators and eventual metrics upon partners and the innovation process itself.

Second funnel

4) Presentation: a complete project plan and ICT analysis are conceived and the business model is eventually refined. This is done by the involved companies 
helped by some external actor (from inside or outside the federation) depending on the VO governance model. It also includes issues of IPR and ownership, accounting, and knowledge gaps in the $\mathrm{VO}$ and in the federation.

5) Software-service conceptualization: it refers to the idealization of the SOA solution, the required services to be composed and expected end-to-end QoS.

6) Software development: this process basically deals with the same issues tacked in the previous step. However, at a much more detailed level, including the services coding themselves, their integration and final verifications. It covers the SOA/services life cycle development [20], but respecting the many particularities when the SOA project is developed by a group of companies [21].

7) SOA solution launching: this process ends the innovation development, making the idealized SOA solution available to who has requested it. Further actions are very much dependent on the business and contract / its term. Therefore, it may include processes that are out of a typical innovation framework, like the SOA product effective provision to clients/customers.

An underlying construct in the proposed innovation model is the VO life cycle. Its importance is twofold: i) knowing in which processes a VO can change its configurations, including partners' entrance/withdrawing and their respective roles; ii) helping partners in the VO management as this requires additional processes for each VO phase other than innovation or software engineering related. These processes have different complexities and demands different efforts, costs and supporting methods from the VO members [22].

\subsection{Functional Guidelines}

Functional guidelines (FG) correspond to supporting aspects that should be considered by network members along the collaborative innovation. It is a construct not presented in other innovation models. They represent methods, techniques, tools and foundations that are required at the different phases of the whole process and at different levels. Ten main FGs have been identified through an inductive method over a number of papers on innovation got from the literature review (e.g. [23] and [24]). FGs are grouped into categories, which act at three levels of the innovation process. Briefly:

- Business level: it embraces the FGs related to the innovation commercialization, in more particular: Business Model management - guarantee that the innovation results are aligned with the defined business model; Legal management - guarantee that the innovation results have been developed and are aligned within the required legal framework, respecting contracts, IPR and services ownership.

- Operational level: FGs to support the "daily" operation of the innovation development, in more particular: Actors' management - guarantee that all the involved actors will consider their rights and duties according to the governance model; Project/Resources management - it supports the usual issues related to manage the innovation process as a project, e.g. financial, HR and material resources; Network operation - it is also related to the governance model, adapting the power and structural elements of decision-making; Incentive systems - issues to guarantee the correct application of collaboration incentives in the innovation also regarding productivity and adherence to the project's goals; Performance indicators: selection and application of adequate indicators to correctly measure and manage the performance of the project, individual services, partners and the innovation itself.

- Policies level: FGs related to general relations among the VO, the VO with other actors (internal or external to the federation), and with customers, in more particu- 
lar: Governance - rules and models to set up how the innovation will be executed and managed; Software process improvement - models, standards, specifications, practices and methodologies to guarantee the right way of developing software and services; Knowledge sharing - to guarantee that the necessary information and knowledge to support the innovation are properly shared and managed.

\section{Final Considerations}

This paper has presented preliminary results of a research which aims at conceiving an innovation model devoted to support collaborative innovation among SMEs of software/ services providers towards a SOA solution.

The proposed model has been developed in the light of Collaborative Networks, enabling SMEs to work as a network, so sharing costs, risks and benefits. A Virtual Organization (VO) represents the group of SMEs that jointly carry an innovation out. One of the underlying assumptions is that they should come from a VBE-like network of ICT companies which should have some preparedness to collaborate, which includes sharing of common principles and operating rules.

It could be observed that quite few works have dealt with collaborative innovation targeting networked SMEs and anyone looking at the software services sector and related products. Besides that, most of the innovation models that have been proposed are directed to manufacturing, a sector very different than the SOA/software sector.

The proposed model also identifies the most relevant supporting issues that should be taken into account along the innovation process and the VO life cycle. To be highlighted the governance issue, fundamental to guarantee the correct evolution of a given innovation as long as it progresses, regulating partners' roles, rights and duties. This mitigates conflicts among companies and hence the innovation risks. Such issues, taken as functional guidelines in the proposed model, help companies to allocate proper resources and to be aware about different levels of complexities along the collaborative innovation life cycle. These FGs and their placement along the innovation process should however be seen here as a reference. Therefore, regarding the particularities of the given ecosystem in terms of e.g. existing culture, type of customers, adopted business models, and regional/national/international accounting and legal frameworks and associated requirements, they can support processes in a different way as and can have different degrees of importance. Yet, new FGs can also be added.

Regarding the particularities of software/SOA sector, the nature of the innovation process, and the fact companies should work in a network, the classical innovation funnel was adapted and split into two sequential but decoupled funnels.

Next steps of this research include the verification of the model and its elements (for further refinements) close to a real cluster of ICT/SOA providers already identified. This also comprises refinements on top of the work of [21] in terms of detailed processes and practices to develop SOA collaboratively with a focus on innovation.

\section{References}

1. http://www.ukita.co.uk/about-ukita/about-ukita.html

2. I. Westphal, K. D. Thoben and M. Seifert, "Managing collaboration performance to govern virtual organizations", in Journal of Intelligent Manufacturing, Vol 21/3, pp.311-320 (2010)

3. Y. Li, J. Shen, J. Shi, W. Shen, Y. Huang, and Y. Xu, "Multi-model driven collaborative development platform for service-oriented e-Business systems", Advanced Engineering Informatics, vol. 22, pp. 328-339 (2008)

4. PRWEB,http://www.prweb.com/releases/soa-services-oriented/architecture market/prweb10670370.htm 
5. Rabelo, R.J.: Advanced collaborative business ICT infrastructures. Methods and Tools for collaborative networked organizations, pp. 337-370. Springer (2008)

6. Tidd, J., Bessant, J., Pavitt, K.: Innovation Management. Willey (2001)

7. N. D. Du Preez and L. Louw, "A framework for managing the innovation process", in Proc. Portland Int. Conf. on Management of Engineering \& Technology, pp. 546-558 (2008).

8. Rothwell, R.: Successful industrial innovation: critical factors for the 1990s. R\&D Management 22, 221-240 (1992)

9. Baldo, F., Rabelo, R.J.: For a methodology to implement virtual breeding environments-a case study in the mold and die sector in Brazil. Leveraging Knowledge for Innovation in Collaborative Networks, pp. 197-206. Springer (2009)

10.Malerba, F.: Sectoral systems of innovation: concepts, issues and analyses of six major sectors in Europe. Cambridge University Press (2004)

11.Roth, A.L., Wegner, D., Padula, A.D.: Differences and Inter-Relations of Governance Concepts and Horizontal Networked Enterprises Managemen. Journal of Administration [in Portuguese], vol. 1, pp. 112-123, São Paulo, Brazil (2012)

12.Costa, S.N., Rabelo, R.J.: "A Governance Model for Virtual Enterprises" [in Portuguese]. in Proc. XVI Symposium on Manufacturing Management, Logistics and International Operations, pp. 1-12, São Paulo, Brazil (2013)

13.Storper, M., Harrison, B.: Flexibility, hierarchy and regional development: The changing structure of industrial production systems and their forms of governance in the 1990s. Research Policy 20, 407-422 (1991)

14.Gereffi, G., Humphrey, J., Sturgeon, T.: The governance of global value chains. Review of international political economy 12, 78-104 (2005)

15.Kitchenham, B., Pearl Brereton, O., Budgen, D., Turner, M., Bailey, J., Linkman, S.: Systematic literature reviews in software engineering - A systematic literature review. Information and software technology 51, 7-15 (2009)

16.A. J. Berre, Y. Lew, B. Elvesaeter, and H. de Man, "Service Innovation and Service Realisation with VDML and ServiceML", in 7th IEEE International Enterprise Distributed Object Computing Conference Workshops (EDOCW), pp. 104-113 (2013)

17.Hoyer, V., Christ, O.: Collaborative e-business process modelling: a holistic analysis framework focused on small and medium-sized enterprises. Proceedings 10th international conference on Business information systems, pp. 41-53. Springer, Poznan, Poland (2007)

18.Belussi, F., Arcangeli, F.: A typology of networks: flexible and evolutionary firms. Research Policy 27, 415-428 (1998)

19.http://cordis.europa.eu/projects/home_en.html, accessed in Sept 2013.

20.L. O'Brien, "A framework for scope, cost and effort estimation for service oriented architecture (SOA) projects", in Software Engineering Conference, ASWEC'09, Australia, pp. 101$110(2009)$

21.M. H. Cancian, R. J. Rabelo, and C. G. von Wangenheim, "Supporting Processes for Collaborative SaaS," in Proc. 14th IFIP Working Conference on Virtual Enterprises, Springer, pp. 183-190 (2013)

22.Camarinha-Matos, L., Afsarmanesh, H.: Collaborative Networks: Reference Modeling. Springer Publishing Company, Incorporated (2008)

23.S. Munkongsujarit and S. Srivannaboon, "Key success factors for open innovation intermediaries for SMEs: A case study of iTAP in Thailand", in Proceedings of PICMET'11 Technology Management in the Energy Smart World, pp. 1-8 (2011)

24.J. Van Zyl, "Process innovation imperative [software product development organisation]," in Proceedings IEMC'01 - Change Management and the New Industrial Revolution, pp. 454$459(2001)$ 